\title{
Justice in the Tea Estate Community in Sri Lanka: An Explanation through Freedom-based Capability Approach
}

\author{
Sajitha Dishanka ${ }^{*}$, Yukio Ikemoto ${ }^{2}$ \\ ${ }_{1}^{1}$ Department of Business Economics, University of Colombo, Sri Lanka \\ ${ }^{2}$ Institute for Advanced Studies on Asia, The University of Tokyo, Japan \\ *sajitha@dbe.cmb.ac.lk
}

\begin{abstract}
Sustainability in economic development is fundamentally linked to human well-being which should be fairly reflected in freedom. This normative concern has been the thematic phenomenon in scholarly discussions advocated by many egalitarians. The well-being of tea estate community in Sri Lanka has been in various stakeholder discussions as their socio-economic freedom is exogenously determined and controlled. Ironically, this situation has evidenced a substantial adverse impact on their present work performance and future workforce participation symbolizing the labor problem within the tea estate community. Grounded on the theoretical foundation of Amartya Sen's capability approach and, authors' mixed method field surveys, this paper discusses the importance of enhancing justice within this community by improving their freedom to access better complex capabilities such as social status and independence. Although, the outcomes of the positivistic study provided with adequate evidence for the above claim, our qualitative inquiry confirmed and witnessed the aforementioned subjective reality.
\end{abstract}

Keywords: Capabilities, freedom, Sri Lanka, tea estate community, well-being

\section{Introduction}

The concept of human development has emerged in 1990 as an alternative development paradigm which embraced emphasis on advancing the richness of human life rather than the richness of the economy which is more materialistic(Edewor, 2014).Although Sri Lanka has reported significant economic improvements in the recent past as a developing nation, the regional human development aspect has not been satisfactory as far as the livelihood of the tea estate community is concerned. Many scholars and stakeholders had repeatedly addressed the poor basic capabilities (low income, poor health, insufficient nutrition, low quality housing) and poor work performance (low labor productivity) of this communal workforce. However, none of them were able to discuss their poor complex capabilities (poor social condition characterized with lower social status and independence) and its impact on their work performance. In the last couple of decades stakeholder activists such as employers and their representatives, and the national government have launched many development oriented programs to provide them with basic capabilities. However, the success of those attempts had not been adequately reflected in their work performance as the focus of those programs were community-wide and, some of those have been partial in which the target group has not been directly benefited(Dishanka \& Ikemoto, 2013). The main reason for this failure is that, the activists have been unable to identify and address the tea estate workers' complex capabilities and freedom to achieve what they really value. This has done injustice to this community as valued capabilities vary from basic freedoms such as being free from hunger and undernourishment to complex capabilities such as achieving self-respect and social participation(Sen, 2003).This unwholesome scenario has apparently headed the tea plantation sector of Sri Lanka toward a risky condition necessitating a sustainable solution to assure steadiness in future labor supply and performance.

In this paper we firmly stress the importance of a significant improvement in the social condition of the tea estate community which enables them to enjoy freedom as a core and pre-requisite of their human development, which eventually would reflect in enhanced work performance and encouraged participation in estate workforce. According to the major findings of our previous study(Dishanka \& Ikemoto, 2013), the labor problem of the tea estate community in Sri Lanka can be synthesized into a capability problem due to lack of freedom. Apparently, absence of independence in existing employment practices and culture-bound traditions have become social barriers (social conversion factors), while gender, age, education and income variations are being personal factors (personal conversion factors) in achieving valued functioning of this community, which has eventually resulted in poor work performance, and low labor force participation due to migration. Accordingly, we could categorize the following problem areas in our study. 
- Although recent improvement in estate education and income has given better opportunities for new generations, such development has not considerably reflected in their social lives in estates. Therefore, labor out-migration has become very widespread especially among the youth in the labor force. Thus, future labor supply of the tea estate sector is at high risk due to the lack of participation of the younger generation in the labor force.

- Estate community in Sri Lanka has a diverse set of cultural attributes which have evolved from generations. Major component of the total factor productivity of the tea estates is handled by women workers as tea pluckers in the estate. As far as tea estate sector in Sri Lanka is concerned, women are responsible for all kind of household activities in addition to their full-day work in the tea estate whilst the male workers are working half a day. This evidences the gender discrimination in tea estate work norms which are determined and controlled by their traditional culture.

- In the process of human development, it is essential for an individual to be his/her agent in making decisions related to his/her well-being. Individuals should be identified as independent agents, who have their own goals, make their own choices, and not mere receptacles for resource-inputs and satisfaction (Gasper, 2007).Valued freedom of individuals should not be severely violated as a result of this collective effort. In this perspective, the opportunity and process freedom of this community is thus questionable if their socio-economic decisions are exogenously controlled.

Hence, we firmly believe that, providing this community with required and expected freedoms in achieving complex capabilities would eventually minimize the prevailing labor problem. In order to achieve this objective, we have concentrated our survey findings on the theoretical foundations and explanations of Amartya Sen's freedom-based capability approach. We have identified freedom as the major requisite of justice in the tea estate community and, well-being freedom and agency freedom as its main dimensions in operationalizing it in our study. Accordingly, the result and the findings of the study are signified in the above two aspects of practical importance. These two aspects are required to be considered and incorporated in the future decisions and initiatives, respectively by the major stakeholders such as employers and their agents, employees' agents and the government with respect to the estate community in their effort of searching or developing a sustainable solution for the chronic labor problem in the tea estate sector in Sri Lanka. The succeeding sections of this paper elaborate the related literature survey conducted, followed by the research methods adopted. Subsequent section provides an analysis of survey data and qualitative findings upon which the discussion and the conclusion were grounded.

\section{Literature Review}

Capabilities and human development: Perhaps the most important thematic deficiency of classical development economics is its concentration on national product, aggregate income and expenditure, national saving and investment rather than on 'entitlements' of people and the 'capabilities' that these entitlements generate (Sen, 1983). After the first Human Development Report (HDR) of the United Nations Development Program (UNDP) in 1990, there was a considerable shift in defining 'development' from economy aspect to people aspect (more precisely, the human development aspect). With this paradigm shift, the assessment of development changed from economic indicators (such as growth rate, per capita income, trade surplus, unemployment rate, etc.) to what people can do and be in their lives. The human development paradigm is concerned both with building up human capabilities through investment in people and with using those human capabilities fully through an enabling framework for growth and employment (Ul-Haq, 2003). According to Sen's capability approach, the ability and freedom of a person to achieve what he/she values, determines that person's development as it reveals his/her socio-economic well-being. However, gaining the freedom to do the things that we have reason to value is rarely something we can accomplish as individuals (Evans, 2002). Seen from this viewpoint, development is about removing the obstacles such as illiteracy, ill health, lack of access to resources, or lack of civil and political freedoms to what a person can do in life (Fukuda-Parr, 2003).The two important aspects associated with human capabilities are process and opportunity aspects of freedom. Violation of process aspect is being forced to do something even though it is an action an individual would have freely chosen also. Violation of substantive opportunity freedom is forcing an individual to do what an individual does not like to do when that person has any plausible alternative (Sen, 2005). It is important to recognize that, both processes and opportunities can figure powerfully in the content of human rights. Although, human rights and human capabilities share the same motivation seemingly, these 
two are distinctive in socio-political spheres. Therefore, it is required to formulate the norms as a set of capabilities for fully human functioning while maintaining the cross-cultural diversity(Nussbaum, 1999).

Culture, gender and capabilities: In real life, ideas of the good life are profoundly influenced by family, tribal, religion, community or cultural ties and background (Robeyns, 2005). Culture is community based phenomenon which specifies a set of traditions and norms to shape the behavior of individuals in that community group. Sen and other feminist scholars have paid much attention to the social norms and traditions that form women's preferences, and that influence their aspirations and effective choices in social groups. Many feminist researchers have addressed the lower status and heavy burden of estate women within the household and working environment (Nussbaum, 2000); (Raynolds, 2002); (Philips, 2003); (Iversen, 2003). This has been defined as the 'double burden' of tea estate women in an extremely male dominant estate community culture (Samarasinghe, 1993).In many traditional societies in the world, women are lacking both the freedoms of voice and choice(Jayawardena, 1984). In making a decision whether to participate in labor market, they have to concern about cultural factors, social attitudes, gender role patterns and many other demographic factors (Eberharter, 2001). However, women in the third world are lacking agency and their roles played in both private and public domains are not adequately discussed(Chua, Bhavani, \& Foran, 2000). Women in much of the world, lack support for fundamental functions of a human life. They are less well-nourished than men, less healthy, and more vulnerable to physical violence and sexual abuse (Nussbaum, 2000).

Physical or psychological spousal abuse seriously undermines women's capability to function and to live the lives they value(Panda \& Agarwal, 2005). They are much less likely than men to be literate, and still less likely to have pre-professional or technical education. However, despite these comparatively negative attributes of women in the third world, they have become the key determinant of technical efficiency in many production systems. Apparently, they are the core factor in determining the productive efficiency of tea manufacturing in Sri Lanka's estate sector as it is based on the tea plucking efficiency of female workers. Although there was a significant improvement in tea estate female workers' income in the past, it has not necessarily reflected in their capabilities in the form of empowerment (Samarasinghe, 1993).Changing the culture in order to inculcate gender equity and a conducive work atmosphere cannot be done from outside. Although it is challenging, this change should be introduced by the systems and programs initiated within that same society in concern (Philips, 2003). However, introducing such change into a society with deeply rooted cultural norms and beliefs are rather challenging unless the leaders from that society participate in the change process.

Migration and well-being: Migration from agriculture occurs when there is a departure of individuals or households for more than a week or so, from the small, primarily agricultural community in which they live (Lipton, 1980). He further stated that, migration takes away the young with more capabilities aged $15-25$ years who are often most significant agricultural innovators. Migration and its impact on socio-economic development of sending and receiving communities have been extensively discussed by both functionalists and structuralists. These two paradigms advocate for two opposing views on this phenomenon. Functionalist paradigm grasps the neo-classical view which is more optimistic on migration and development, whereas structuralist paradigm represents the neo-Marxist view which is highly pessimistic(De Haas, 2010). Representing the neo-classical migration theories, in the dualistic model of migration and development argument it has been specifically stated that rural-urban labor migration not only continues to exist, but indeed, appears to be accelerating, despite the existence of positive marginal products in agriculture and significant levels of urban unemployment(Harris \& Todaro, 1970). The incentive to migrate is not a function of income levels but rather, and exclusively so, of income differentials (Stark \& Yitzhaki, 1988). Migration that occurs on an expected wage, will locate the migrant himself on a lower well-being utility curve(Harris \& Todaro, 1970). However, with emergence of new economic theories and models on labor migration, more motives for migration were identified. With this emergence, the migration has been identified as a part of the risk-sharing behavior of families or households (De Haas, 2010). This migration has a second round effect as the feedback of migrants induces the non-migrants who are relatively deprived (Stark, 1991). The main negative impact of such migration on the development of the sending community is through an increase in inequality(De Haas, 2010).However, due to this migration sometimes the migrant enjoys their freedom of choice even though their achieved material well-being diminishes(Alkire, 2005).

\section{Methodology}


Theoretical framework: In this paper, we have grounded our arguments and discussion on Sen's Freedombased Capability Approach for achievable/achieved well-being. The concepts, variables, and its interrelationships are illustrated in the theoretical framework in figure 1. The capability approach conceptually explains, achieving what a person value depends on his/her abilities of converting the goods and services available into achievable functioning known as that person's capability set. However, the ability of this conversion mainly depends on his/her personal factors (e.g. physical condition, sex, skills, intelligence, etc.) and socio-environmental factors (e.g. public policies, social norms, gender roles, societal hierarchies, power relation, geographical context, etc.) of the social group and the environment that individual belongs to.

Figure 1: Freedom-based capability approach for achieved well-being

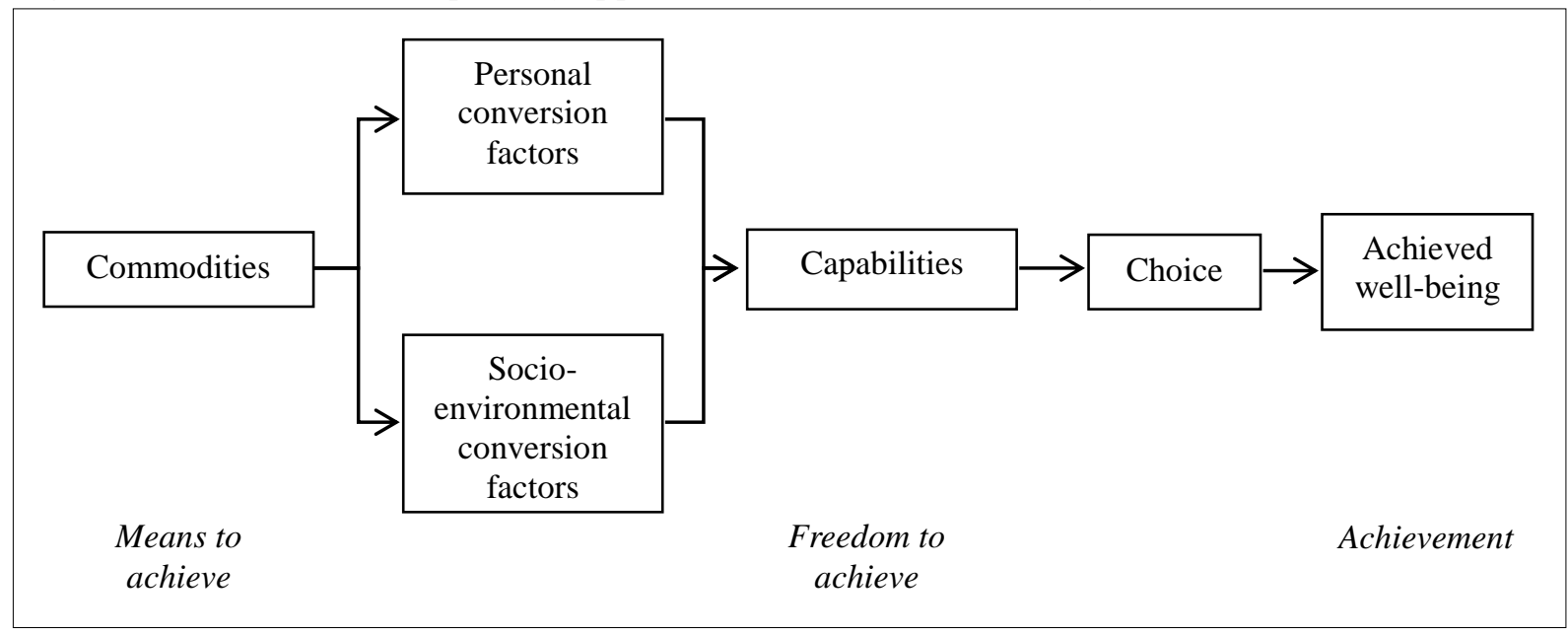

Based on the influence of these factors, the capability set with achievable functioning will be formed. Ultimately, the freedom of choice of that individual determines what he/she should achieve and thereby the individual himself reach a certain well-being level which is valued. More precisely, Sen's claim is that wellbeing achievements should be measured in functioning, whereas well-being freedom is reflected by an individual's capability set (Robeyns, 2005). Availability or simply the possession of commodities does not explain an individual's well-being and the achievements if that individual does not necessarily experience a freedom.

Operationalization: As per the main objective and theoretical model in figure 1, the freedom of the tea estate community was operationalized in three nominal indicators. Specifically, those are; (i) future migration intention, (ii) preference for a change in traditional work norms, and (iii) preference to be independent farmers. In order to regress these three variables; gender, age, educational attainment, monthly estate income of tea estate workers were used as predictor variables which are either nominal or ordinal. However, in the above causality we have identified estate workers' satisfaction on estate management as a mediator variable which may hold controlling power.

Sampling and Data collection: Primary data were gathered through questionnaire based interviews conducted with a stratified sample of 105 tea estate workers from different working families belong to RPCs in high-elevation tea estates in Nuwara Eliya and Badulla districts in Sri Lanka. The interviews were conducted as mutual discussions due to the ethnographic nature of the study as the respondents were attributed with specific socio-cultural characteristics. Moreover, livelihood of those workers and their families were directly observed in order to secure validity and reliability of responses received from the questionnaire. The discussion of the quantitative survey results was accompanied with the ethnographic interview findings and observations. In selecting the sample of 105 workers, gender and age were mainly considered as these personal factors have a high impact on individual capabilities and valued achievements in the tea estate sector of Sri Lanka. Accordingly, 56 male workers of whom 24 were within the age category of 16 - 25years and 32 were above 25 years of age. The female strata of 49 consist of 15 workers from the $16-25$ years of age 
category and 34workers are 26 years of age or more. The reason for such focus is predominantly driven by the future labor supply problem of the tea estate sector.

Method of analysis: The researchers' attempt in this study is to explore a conceptual social phenomenon with respect to a social context. Thus, the study turned out to be intrinsically interpretive. However, the researchers' normative explanations required to be sufficiently evidenced and supported by positivistic findings. Hence, the analysis was initiated with a data description and independent samples test for equality of means and variances of basic parameters. Subsequently, the variables were quantified using a correlation analysis (Multicollinearity) and dichotomous logistic regression (DLR) analysis of which the results were critically assessed and discussed with the findings of the qualitative inquiry. Thus, mix method was adopted as the key research methodology as merely the positivistic study itself does not do justice to the social phenomenon under study as the reality was quite subjective in this social context. The correlation analysis was preoccupied in order to identify and measure the probable influences of correlations between variables on the outcomes of the regression analysis. Thus, it enables the inclusion and exclusion of variables in regression analysis.

\section{Results, Findings and Discussion}

The first Human Development Report in 1990 declared, human development is not merely improving the access to basic capabilities; it is the process which widens people's choices and the level of their achieved well-being. Many scholars and stakeholders have addressed that the basic needs of the tea estate community such as housing, education, health and nutrition are well-below the expected standard requirements. Based on this, employers and their representing organizations launched different projects to uplift those conditions. However, our fieldwork observations revealed that those initiatives were just restoration of the aforementioned basic requirements. Redistribution to the poor in the form of improving their health, education and nutrition is not only intrinsically important in enhancing capabilities to lead more fulfilling lives (Anand \& Sen, 2000).

Complex capabilities of an individual include social recognition, self-esteem, participation in decisions, etc. Every individual has his/her own needs hierarchy ranging from physical needs to self-actualization needs. If an individual sees his/her future path of this ultimate achievement, it would probably be a motivation factor for him/her to achieve such level through the work performance. Being a lower level field worker throughout the working tenure (without appreciations, rewards and promotions) has hindered the estate workers' ability of achieving a higher social status. Further, their education level has not been sufficient for them to access complex capabilities with higher social status and independence. Hence, most of them had to confine their lives to tea estates without adequate interaction with outer communities. More precisely, social exclusion phenomenon is highly attributed with this socially deprived community. Lack of social status and job recognition has predominantly influenced many youth in the tea estate community to keep them out of the tea estate sector labor force.

Table 1: Descriptive statistics

\begin{tabular}{llllll}
\hline & Gender & $\mathbf{N}$ & Mean & Std. Deviation & Std. Error Mean \\
\hline Age & Female & 49 & 2.55 & 1.501 & .214 \\
\multirow{2}{*}{ Education } & Male & 56 & 2.14 & 1.407 & .188 \\
\multirow{3}{*}{ Estate income } & Female & 49 & 2.27 & .811 & .116 \\
& Male & 56 & 2.21 & .803 & .107 \\
Satisfaction & Female & 49 & 1.53 & .504 & .072 \\
& Male & 56 & 1.52 & .660 & .088 \\
& Female & 49 & 3.14 & 1.339 & .191 \\
& Male & 56 & 2.91 & 1.269 & .170 \\
\hline
\end{tabular}

The descriptive statistics in table 1 in favor of two independent gender groups have been obtained with 
respect to the ordinal explanatory variables used in subsequent analysis. Although, the statistics of main explanatory variables do not seem to be different between gender groups, an independent samples test at 5 percent significance level was conducted to statistically verify the equality of means and variances of male and female sample groups (see Table 2). The results of Levene's test for equality of variances statistically confirmed that there is a significant variance (0.023) only in estate income of two gender groups. The result of the samples t-test for equality of means confirmed that there is no sufficient statistical evidence to ascertain any significant difference between sample means of explanatory variables. Accordingly, this preliminary statistical analysis confirms the existence of income inequality between male and female workers in the tea estate sector.

Table 2: Independent samples test

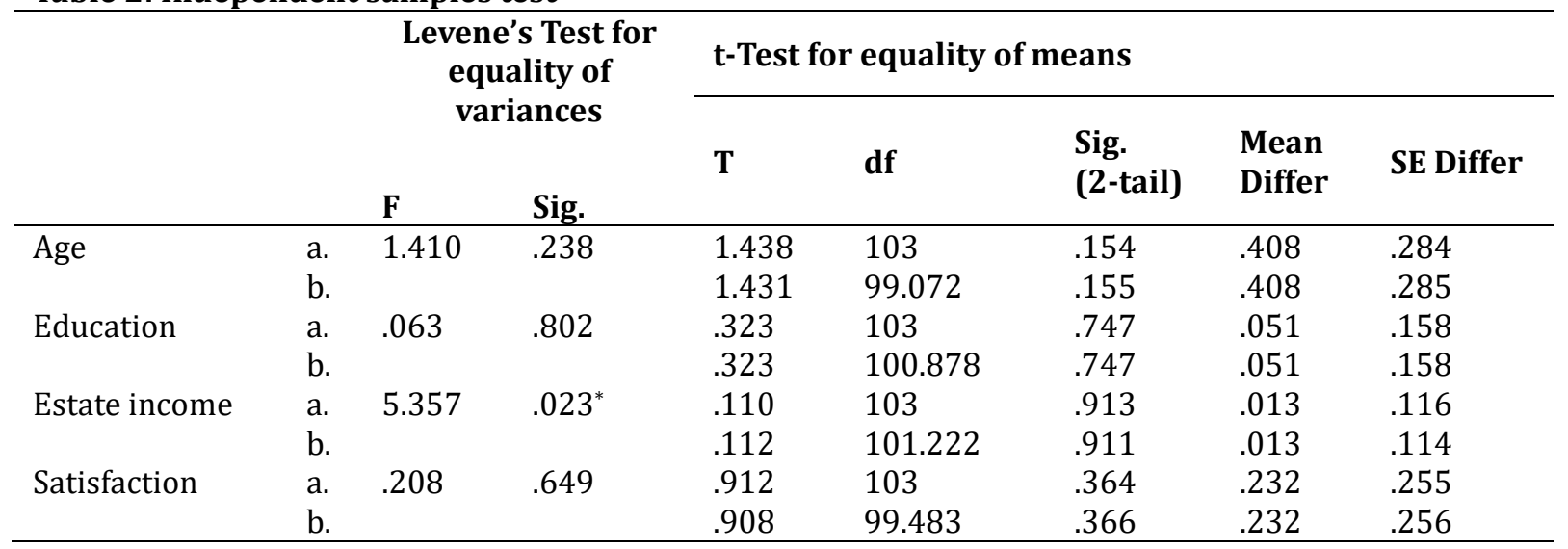

a. equal variances assumed

b. equal variances not assumed

${ }^{*} p<.05$ (two-tailed)

As depicted in the conceptual model, human capabilities (importantly, complex capabilities) are subject to personal and social conversion factors. According to the results of the analysis (see Table 3), gender, age educational attainment, and monthly estate income have depicted significant correlations with other variables confirming the role of being personal conversion factors in tea estate workers' capabilities and wellbeing. However, none of these significant correlations are strong as the coefficient values are below \pm 0.5 . The results of the analysis in table 3 , evidently highlights that age of the estate worker as a personal conversion factor is significantly correlated with many other variables. Although, age is negatively correlated with educational attainment $(-0.462)$, it explains a positive relationship with monthly income earned from estates $(0.343)$ at 1 percent level of significance. This insinuates that educational attainment has not reflected in the estate earnings of the youth. Low educational attainment of adult workers has become a major personal factor in converting their income into productive use. According to the field survey, 53 percent of the tea estate workers have not schooled more than 5 years and this attribute was high among adult male (81\%) and adult women (59\%) in the sample. The significant negative correlation between age of the worker and future migration intention (-0.341) signals a potential magnification of the future labor supply problem of the tea estate sector due to potential migration of the youth from the tea estate labor force.

Table 3: Correlation matrix

\begin{tabular}{|c|c|c|c|c|c|c|c|c|c|}
\hline & & 1 & 2 & 3 & 4 & 5 & 6 & 7 & 8 \\
\hline 1 & Gender & 1 & & & & & & & \\
\hline 2 & Age & -.140 & 1 & & & & & & \\
\hline 3 & Education & -.032 & $-.462^{* *}$ & 1 & & & & & \\
\hline 4 & Estate income & -.011 & $.343^{* *}$ & -.164 & 1 & & & & \\
\hline 5 & Satisfaction & -.089 & .042 & -.060 & .012 & 1 & & & \\
\hline 6 & Future migration & .059 & $-.341^{* *}$ & $.327^{* *}$ & $-.330^{* *}$ & -.027 & 1 & & \\
\hline 7 & Change work norms & .013 & $-.324^{* *}$ & .050 & -.104 & -.102 & .040 & 1 & \\
\hline
\end{tabular}




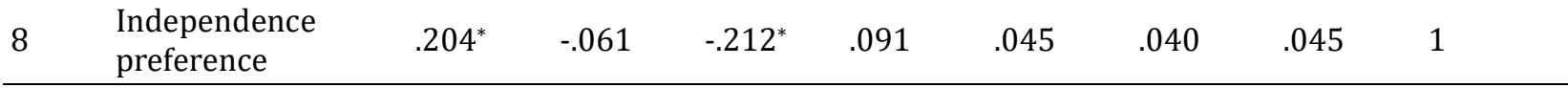

Note: $N=105 .{ }^{*} p<.05$ (two-tailed); ${ }^{* *} p<.01$ (two-tailed)

Although, the radical expectation of the youth for a change in the existing traditional work norms $(-0.324)$ provides a positive indication towards the future, failure of the decision makers and policy makers in implementation of such, probably worsen the aforementioned labor supply problem. This adverse condition is further confirmed by the significant positive causality (0.327) between educational attainment and future migration intention. However, the analysis confirms that there is a significant negative correlation $(-0.330)$ between income earned from estate employment and intention to migrate, inferring the possibility of retaining the estate youth providing them with enhanced opportunities for higher earnings. This implication is further confirmed by the significant negative correlation $(-0.212)$ between educational attainment and preference to be independent farmers. However, such preference is apparent among the male workers (0.204) inferring the deeply rooted dependence culture of the estate women.

According to the outcomes of the multicollinearity analysis (see Table 3), we conducted the DLR analysis with a view of identifying categorical correlation of aforementioned three indicators of freedom (future migration intention, traditional work norm change preference, and preference to be independent farmers) in the tea estate community in Sri Lanka. However, level of satisfaction on the estate management was excluded from the DLR analysis as it did not convince any significant relationship with any of the personal conversion factors and freedom indicators in correlation analysis in table 3. It inferences, that tea estate workers' relationship with the estate management is fairly neutral. Nevertheless, this was discussed in our qualitative inquiry as it provided significant inference toward the freedom indicators of this community. The cross-tabulation result in table 4 confirms that gender variation within the estate community and workers' migration intention are statistically independent. Therefore, gender was excluded from the DLR analysis and the result in table 5 was obtained.

Table 4: Cross-tabulation (Gender and future migration intention)

\begin{tabular}{|c|c|c|c|c|}
\hline \multirow[b]{2}{*}{ Future migration } & \multicolumn{3}{|c|}{ Gender } & \multirow[b]{2}{*}{ Total } \\
\hline & & & 2 (Male) & \\
\hline $0(\mathrm{No})$ & & & $31(55.4 \%)$ & $61(58.1 \%)$ \\
\hline 1 (Yes) & & & $25(44.6 \%)$ & $44(41.9 \%)$ \\
\hline Total & & & $56(53.3 \%)$ & $105(100.0 \%)$ \\
\hline Chi-Square & Value & Df & Sig & \\
\hline Pearson & $.370^{\mathrm{a}}$ & 1 & .543 & \\
\hline Likelihood Ratio & .370 & 1 & .543 & \\
\hline
\end{tabular}

a. 0 cells (.0\%) have expected count less than 5. The minimum expected count is 20.53

Table 5: Dichotomous logistic regression for future migration intention

\begin{tabular}{llll}
\hline & B & S.E. & Exp(B) \\
\hline Constant & -.555 & .705 & .574 \\
Age $(16-25)$ base & & & \\
$26-35$ & -.040 & .520 & .961 \\
$36-45$ & -.416 & .765 & .660 \\
$46-55$ & -.441 & .827 & .644 \\
$56-65$ & -20.244 & $1.531 \mathrm{E} 4$ & .000 \\
66 \& above & -20.388 & $1.753 \mathrm{E} 4$ & .000
\end{tabular}

Education (No schooling) base 


\begin{tabular}{llll} 
Up to Grade 5 & .732 & .737 & 2.080 \\
Grade $6-10$ & $1.369^{*}$ & .714 & 3.930 \\
Income $(10,000-15,000)$ base & & & \\
$15,000-20,000$ & $-.799^{*}$ & .483 & .450 \\
$20,000-25,000$ & -21.018 & $1.652 \mathrm{E} 4$ & .000 \\
-2 log likelihood & 113.672 & & \\
Model chi-square & $29.125^{* * *}$ & & \\
Nagelkerke pseudo R & & \\
Hosmer and Lemeshow test & 0.326 & & \\
\hline
\end{tabular}

Note: $N=105 ;{ }^{*} p<.1 ;{ }^{* *} p<.05 ;{ }^{* * *} p<.01$

Although, the outcome appeared to be rather passive with lack of significant variables, the model reflects the reality as confirmed by the chi-square statistic which is being highly significant at 1 percent level of significance. The model explains that the workers with the highest educational attainment in the sample are having an intention to migrate from estate work. However, it confirms that the moderate level income (LKR 15,000 to 20,000 ) category is significantly showing less preference to migrate indicating their retention. Even in the preference to change the traditional work norms as a social conversion factor of tea estate community's capabilities, gender has been independent as depicted in table 6. In capability expansion through changes in traditional work norms, 26-35 middle age category and 46-55 upper age category have significantly disclosed discontentment (see Table 7).

Table 6: Cross-tabulation (Gender and preference to change traditional work norms)

\begin{tabular}{llll}
\hline \multicolumn{2}{l}{ Gender } & \multicolumn{1}{c}{ Total } \\
\cline { 2 - 3 } Change work norms & $\mathbf{1}$ (Female) & $\mathbf{2}$ (Male) & $55(52.4 \%)$ \\
\hline $0($ No) & $26(53.1 \%)$ & $29(51.8 \%)$ & $50(47.6 \%)$ \\
1 (Yes) & $23(46.9 \%)$ & $27(48.2 \%)$ & $105(100.0 \%)$ \\
Total & $49(46.7 \%)$ & $56(53.3 \%)$ &
\end{tabular}

\begin{tabular}{llll}
\hline Chi-Square & Value & df & Sig \\
\hline Pearson & $.017^{\mathrm{a}}$ & 1 & .896 \\
Likelihood Ratio & .017 & 1 & .896
\end{tabular}

a. 0 cells (.0\%) have expected count less than 5. The minimum expected count is 23.33

This situation is much strong within the 46-55 age category due to two possible causes. First, these are the workers those who have considerable power both at estate level and household level. Second, elder workers are usually reluctant to change due to their risk-averse behavior in social and organizational change processes. However, it is quite unusual to see the passive response of the youth for a social transformation confirming their social adherence. This outcome further emphasizes the inadequacy of estate workers' education to demand a radical change in unproductive social systems.

Table 7: Logistic Regression for preference to change traditional work norms

\begin{tabular}{llll}
\hline & B & S.E. & Exp(B) \\
\hline Constant & .939 & .692 & 2.557 \\
Age $(16-25)$ base & & & \\
$26-35$ & $-.974^{*}$ & .519 & .378 \\
$36-45$ & -.324 & .739 & .723 \\
$46-55$ & $-2.442^{* *}$ & .968 & .087 \\
$56-65$ & -1.610 & 1.112 & .200
\end{tabular}


66 \& above

Education (No schooling) base

Up to Grade 5

Grade 6 - 10

Income $(10,000-15,000)$ base

$15,000-20,000$

$20,000-25,000$

$-2 \log$ likelihood

$-21.588$

$-.091$

$-.322$

$-.513$

1.832

122.498

Model chi-square

$22.825^{* * *}$

Nagelkerke pseudo $\mathrm{R}^{2}$

0.261

Hosmer and Lemeshow test

0.647
$1.794 \mathrm{E} 4 \quad .000$

.698

1.095

.725

.599

6.244

Note: $N=105 ;{ }^{*} p<.1 ;{ }^{* *} p<.05 ;{ }^{* * *} p<.01$

Despite the fact that gender is impartial in migration intention and traditional work norm change, it is materialized to be a significant predictor of being independent farmers (see Table 8). Notably, this preference to be an independent farmer has been contently expressed by male workers implying their social power within the community (see Table 9).

Table 8: Cross-tabulation (Gender and preference to be an independent farmer)

\begin{tabular}{|c|c|c|c|c|}
\hline \multirow{2}{*}{\multicolumn{2}{|c|}{ Independence preference }} & \multicolumn{2}{|c|}{ Gender } & \multirow[b]{2}{*}{ Total } \\
\hline & & 1 (Female) & 2 (Male) & \\
\hline $0(\mathrm{No})$ & & $31(63.3 \%)$ & $24(42.9 \%)$ & $55(52.4 \%)$ \\
\hline 1 (Yes) & & $18(36.7 \%)$ & 32 (57.1\%) & $50(47.6 \%)$ \\
\hline Total & & 49 (46.7\%) & $56(53.3 \%)$ & $105(100.0 \%)$ \\
\hline Chi-Square & Value & $\mathrm{df}$ & Sig & \\
\hline Pearson & $4.364^{\mathrm{a}}$ & 1 & .037 & \\
\hline Likelihood Ratio & 4.399 & 1 & .036 & \\
\hline
\end{tabular}

Conversely, elder community above 66 years of age has significantly voiced their discontent to be independent farmers as would have expected at such elderly age. Tea estate workers in the selected sample with the highest educational attainment (Grade 6-10) have significantly expressed their unwillingness to be independent farmers reconfirming their intention of migrating from tea estate sector.

Table 9: Logistic Regression for preference to be an independent farmer

\begin{tabular}{llll}
\hline & B & S.E. & Exp(B) \\
\hline Constant & .639 & .786 & 1.894 \\
Gender(Male) & $.891^{*}$ & .464 & 2.437 \\
Age $(16-25)$ base & & & \\
$26-35$ & .045 & .526 & 1.046 \\
$36-45$ & -1.012 & .825 & .364 \\
$46-55$ & .028 & .818 & 1.028 \\
$56-65$ & -1.565 & 1.128 & .209 \\
66 \& above & $-2.781^{* *}$ & 1.325 & .062
\end{tabular}

Education (No schooling) base 


\begin{tabular}{llll} 
Up to Grade 5 & -1.124 & .705 & .325 \\
Grade $6-10$ & $-1.854^{* *}$ & .718 & .157 \\
Income $(10,000-15,000)$ base & & & \\
15,000 - 20,000 & .715 & .485 & 2.045 \\
$20,000-25,000$ & .038 & 1.050 & 1.039 \\
-2 log likelihood & 127.363 & & \\
Model chi-square & $17.960^{*}$ & & \\
Nagelkerke pseudo R & 0.210 & & \\
Hosmer and Lemeshow test & 0.886 & & \\
\hline
\end{tabular}

Note: $N=105 ;{ }^{*} p<.1 ;{ }^{* *} p<.05 ;{ }^{* * *} p<.01$

Primarily, in light of the above analysis, the following are identified as the major and immediate areas of intervention by the stakeholders in order to ensure the productive functioning of the tea estate sector in Sri Lanka. These three aspects we have identified and discussed grounded on the three freedom indicators (migration intention, preference to change work norms and preference to be independent farmers) explained in above analysis. We have identified these areas of intervention based on the results of the above explanatory study and the findings of the exploratory study which was grounded on qualitative aspect of the inquiry.

Less focus on the youth and their capabilities: As far as the future production possibility and the productivity are concerned, the participation of the youth in the labor force is a predominant factor in any economy. Thus, the attraction and retention of such individuals would probably be a sustainable solution for the tea estate sector of Sri Lanka, which happened to be a dilemma at present. While the correlation result (see Table 3) signifies the relationship of future migration intention with age (negative), educational attainment (positive) and, estate sector income (negative); DLR analysis categorically signified the impact of educational attainment (Grade 6-10) and estate sector income (LKR 15,000-20,000).The reason for the significant absence of age in the DLR analysis is due to the multicollinearity effect (see Table 3) with educational attainment (negative) and estate sector income (positive). Thus, the migration of the youth from the estate sector labor force is apparent with the presence of relatively higher educational attainment and relatively lower income from estate employment. This migration occurs mainly since they cannot enjoy the modern social life style they value by being in the estate sector and lack of career progression in estate employment. They are discouraged of continuing the same traditional estate work that was done by their previous generations. This is why they migrate although their achievable income of post-migration would be less than what they probably can earn from estate employment. The correlation result (see Table 3) between preference to be independent farmers in the estate sector and educational attainment (negative) further confirmed the migration intention of the estate youth.

Social and traditional work norms as a key conversion factor: Although, the correlation result (see Table 3 ) suggests that there is no significant relationship between gender and estate income, the reality is quite different and highly subjective. This is due to relative inequality of income distribution between gender groups in the tea estate sector (see Table 2). According to the traditional work norm, female workers are required to work full day while males engage only half a day in tea estate employment, though both receive an equal daily wage. This proves that the tea estate women are extremely disadvantageous and underprivileged as their freedom is violated in both process and opportunity aspects. This has been the reason for significant disinterest of the adult male (46 to 55 years of age) workers in tea estates to customize the existing inequitable work norms as they might fail to retain their influential power within the community. Although the management of RPCs surveyed in our previous study (Dishanka \& Ikemoto, 2013)attempted to change these capability restricting social and work norms, they were unsuccessful in many occasions due to the toughness of the adherence toward the traditions of this community. Accordingly, a human development essential (maintaining gender equity and empowering women) has not been satisfied in this particular ethnic group by restricting the tea estate women workers' ability to expand their capability set. This nature has considerably and adversely impacted on their level of well-being. This needs special attention of employers 
and policy makers as estate women's capabilities are severely restricted by the traditions of their culture and traditional work norms. In our field survey also we identified that they do not bring out their independent voice due to this cultural impact on their lives. Employers as well have adopted this social norm without customizing it in accordance with the organizational requirements. Therefore, inability of the organizational culture to customize the behavior of its employees has been injustice to the female workers.

Workers' inability to be their own agents: This does not mean that an individual can perfectly be independent behavioral agents in a social setting. It is important for less privileged groups or ethnic minorities to attain this freedom as a collective effort. In this practice political parties and trade unions are holding a pivotal role in these societies. However, as per the human development paradigm, individuals should be able to decide what they need to do for their own satisfaction and development. Although trade unions are important for individuals of the working class to represent them in the issues related to labor relations, overall control of the work and personal life of an individual by the trade union is not expected. In our sample, all the respondents were members of a trade union (we did not include this in our correlation and regression analysis as there is no variation in this variable) which are highly politicized and represent the national political system in light of the support of this working class. Moreover, the correlation analysis in table 3 confirmed that none of the personal conversion factors (gender, age, education and income) or freedom indicators (migration intension, preference for work norm change and preference to be independent farmers) significantly correlated with the worker's satisfaction level with estate management (mediator/ control variable). We could identify through our discussions with the sample respondents that despite of employees' personal intensions, they have to do what they are asked by trade union leaders. Although many workers including the employers purposefully expect a change in the existing traditional work norms, they were unable to implement such a change at the opposition of these unions. Being engaged in any event without an individual's intention and consent even though the outcome of which is something that individual expected anyhow is a violation of that individual's process freedom (Sen, 2005). It was apparent that the trade unions within the estate community have become a critical social conversion factor in practicing workers' independence in their decisions. This condition has inferred that the opportunity freedom and process freedom of individuals of this community is affected to a greater extent at the absence of independence. The main cause of this dependent nature happened to be the low educational attainment of the community members. None of the respondents in the sample was able to reach above ten years of school education which is a major personal conversion factor that eventually reflected adversely on being independent.

\section{Conclusion and Recommendations}

As the core requirement of the capability approach, individuals and social groups should have freedom in both their 'doings' and 'beings' in achieving what they value in their lives. Necessarily, the freedom of an individual should be grounded on that individual's own desire and decision, irrespective of the outcome. However, tea estate community in high grown areas in Sri Lanka is not in a better position to be the agents of their own goals and decisions. If they attempt to make their own decision, there is a high possibility of a decrease in their achieved well-being due to their high dependence and adherence to external influences. Social conversion factors such as politicized trade unions and culture-bound social norms have a considerable negative impact on their freedom. These reasons have become the major underlying barrier which avoids efficient utilization of the human resource in the tea estate sector. Therefore, employers and policy makers should focus on means of improving complex capabilities of this community to uplift their social status and independence by maintaining equity and workers' participation in decisions and processes. This can be done by enabling the people to become their own agents in their own life and decisions. In order to succeed in this, it is highly and timely important to customize the social conversion factors such as traditional work norms and gender discrimination which, border individual capabilities. Decreasing participation of youth in the estate labor force is highly linked with their increasing level of education and low level of income. This migration scenario is further strengthened with their desire to achieve better life style even at a high explicit opportunity cost of living.

This has proved that merely an increase in estate income is not adequate in retaining the potential future migrants and attracting the migrated back to the land. Accordingly, such an increase should be linked with enablers to convert such income into capabilities. This would probably enhance justice in the tea estate 
community and reflect that in their performance. Accordingly, the results and findings of this study have explicitly and implicitly evidenced that introducing mere changes to the basic capabilities probably would not sustain as those do not necessarily address the complex capabilities of workers. It is apparent that the prevailing tea estate system needs a fundamental transformation in finding a sustainable solution for the chronic labor problem. Therefore, it is the high time for the tea estate sector of Sri Lanka to introduce an alternative system that would empower them while maintaining the equity within the community. Hence, we would recommend the introduction of small-scale contract farming system to the tea estate sector which is sufficiently attributed with empowerment and equity fundamentals eventually result in efficient outcomes. Although, this has been a popular global practice, adoption to the Sri Lankan context should be impartially assessed.

\section{References}

Alkire, S. (2005). Why the capability Approach? Journal of Human Development and Capabilities, 6(1), 115135.

Anand, S. \& Sen, A. (2000). Human Development and Economic Sustainability. World Development, 28(12), 2029-2049.

Chua, P., Bhavani, K. \& Foran, J. (2000). Women, Culture, Development: A New Paradigm for Development Studies? Ethnic \& Racial Studies, 23(5), 820-841.

De Haas, H. (2010). Migration and Development: A Theoretical Perspective. International Migration Review, $44(1), 227-264$.

Dishanka, S. \& Ikemoto, Y. (2013). Social Development and Labour Productivity: The Problem and a Solution for the Tea Plantation Sector of Sri Lanka. Colombo Business Journal, 4(2), 67-80.

Eberharter, V. V. (2001). Gender Roles, Labour Market Participation and Household Income Position. Structural Change and Economic Dynamics, 12(3), 235-246.

Edewor, P. A. (2014). A Conceptual Exploration of the Human Development Paradigm. Mediterranean Journal of Social Sciences, 5(6), 381-388.

Evans, P. (2002). Collective Capabilities, Culture and Amartya Sen's Development as Freedom. Studies in Comparative International Development, 37(2), 54-60.

Fukuda-Parr, S. (2003). The Human Development Paradigm: Operationalizing Sen's Ideas on Capabilities. Feminist Economics, 9(2-3), 301-317.

Gasper, D. (2007). What is the Capability Approach? Its Core, Rationale, Partners and Dangers. The Journal of Socio-Economics, 36(3), 335-359.

Harris, J. \& Todaro, M. (1970). Migration, Unemployment and Development. The American Economic Review, 60(1), 126-142.

Iversen, V. (2003). Intra-household Inequality: A Challenge for the Capability Approach? Feminist Economics, 9(2-3), 93-115.

Jayawardena, K. (1984). The Plantation Sector in Sri Lanka: Recent Changes in the Welfare of Children and Women. World Development, 12(3), 317-328.

Lipton, M. (1980). Migration from Rural Areas of Poor Countries: The Impact on Rural Productivity and Income Distribution. World Development, 6(1), 1-24.

Nussbaum, M. (1999). Women and Equality: The Capabilities Approach. International Labour Review, 138(3), 227-245.

Nussbaum, M. (2000). Women's Capabilities and Social Justice. Journal of Human Development, 1(2), 219-247.

Panda, P. \& Agarwal, B. (2005). Marital Violence, Human Development and Women's Property Status in India. World Development, 33(5), 823-850.

Philips, A. (2003). Rethinking Culture and Development: Marriage and Gender among the Tea Plantation Workers in Sri Lanka. Gender and Development,11(2), 20-29.

Raynolds, L. T. (2002). Wages for Wives: Renegotiating Gender and Production Relations in Contract Farming in the Dominican Republic. World Development, 30(5), 783-798.

Robeyns, I. (2005). The Capability Approach: A Theoretical Survey. Journal of Human Development, 6(1), 93117.

Samarasinghe, V. (1993). Puppets on a String: Women's Wage Work and Empowerment among Female Tea Plantation Workers of Sri Lanka. The Journal of Developing Areas, 27(3), 329-340.

Sen, A. (1983). Development: Which Way Now? The Economic Journal, 93(372), 745-762. 


\section{Journal of Social and Development Sciences (ISSN 2221-1152)}

Vol. 9, No. 1, pp. 6-18, March 2018

Sen, A. (2003).Readdings in Human Development: Development as Capability Expansion. (S. Fukuda-Parr, \& A. Shiva Kuma, Eds.) Oxford, UK: Oxford University Press.

Sen, A. (2005). Human Rights and Capabilities. Journal of Human Development, 6(2), 151-166.

Stark, O. \& Yitzhaki, S. (1988). Labour Migration as a Response to Relative Deprivation. Journal of Population Economics, 1(1), 57-70.

Stark, O. (1991). The Migration of Labour. Cambridge \& Oxford: Blackwell.

Ul-Haq, M. (2003). Readings in Human Development: The Human Development Paradigm. (S. Fukuda-Par, \& A. Shiva Kuma, Eds.) Oxford, UK: Oxford University Press. 